\title{
Vulcan and Hestia: High resolution quantification of fossil fuel $\mathrm{CO}_{2}$ emissions
}

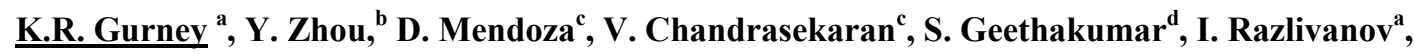 \\ Y.Song ${ }^{a}$, A. Godbole \\ ${ }^{a}$ School of Life Sciences, Arizona State University, Tempe, AZ, USA \\ ${ }^{b}$ Joint Global Change Research Institute, College Park, MD, USA \\ ${ }^{c}$ Department of Earth and Atmospheric Sciences, Purdue University, West Lafayette, IN USA \\ Email:kevin.gurney@asu.edu
}

\begin{abstract}
Here we report on the Vulcan Project (vulcan.project.asu.edu/index.php), an effort to estimate fossil fuel $\mathrm{CO}_{2}$ emissions at local space/time scales through the use of "bottom-up", process-driven information. The Vulcan Project began as an answer to the need for a higher resolution North American fossil fuel $\mathrm{CO}_{2}$ emissions inventory. As a key component in the North American Carbon Program, Vulcan is now playing a critical role as a boundary constraint to inverse estimation of carbon sources and sinks. With the advent of denser $\mathrm{CO}_{2}$ monitoring, both in situ and remote, a higher resolution approach to inventory quantification is essential.
\end{abstract}

The Vulcan Project has estimated United States fossil fuel $\mathrm{CO}_{2}$ emissions at the hourly time scale and at spatial scales below the county level (placed on a regular $10 \mathrm{~km} \times 10 \mathrm{~km}$ grid) for the year 2002 . Vulcan is built from a wide variety of observational data streams including regulated air pollutant emissions reporting, traffic monitoring, energy statistics, and US census data. In addition to these data sets, Vulcan relies on a series of modeling assumptions and constructs to interpolate in space, time and transform non- $\mathrm{CO}_{2}$ reporting into an estimate of $\mathrm{CO}_{2}$ combustion emissions. The recent version 2.0 of the Vulcan inventory has produced advances in a number of categories with particular emphasis on improved temporal structure. Onroad transportation emissions now avail of roughly 5000 automated traffic count monitors allowing for much improved diurnal and weekly time structure in our onroad transportation emissions.

The Vulcan data product has been used for a regional inversion in the US and the potential bias correction from the utilization of previous fossil fuel $\mathrm{CO}_{2}$ emission data products is as high as $100 \%$ for large coherent regions in the United States. This emphasizes the potential for biased fossil fuel $\mathrm{CO}_{2}$ inventories to impact inverse results.

Vulcan has also generated interest from decision-making communities and is now attempting to meet a variety of $\mathrm{CO}_{2}$ mitigation goals by providing process detail on emissions activities. This has led to the Hestia effort in which quantification has been attempted down to the individual building level within a single urban domain (Indianapolis, USA). A partner project, INFLUX, has begun in which the Hestia inventory is combined with aircraft monitoring and flux tower instrumentation to attempt the first urban-level bottomup/top-down comparison. As with Vulcan, the Hestia effort has a variety of decision-support spin-offs including urban planning, energy efficiency planning in addition to $\mathrm{CO}_{2}$ mitigation planning at the urban/street level. Scoping has also begun on performing a Hestia approach for Los Angeles.

Keywords: Greenhouse gas emissions, carbon cycle, high resolution fossil fuel $\mathrm{CO}_{2}$, atmospheric $\mathrm{CO}_{2}$ inversions 


\section{INTRODUCTION}

The largest single net source of $\mathrm{CO}_{2}$ into the Earth's atmosphere is due to the combustion of fossil fuel (Prentice et al., 2001). Efforts to understand and project climate change must therefore rely on an accurate quantification of this flux. Furthermore, understanding the other exchanges of carbon with the atmosphere from the land biosphere and oceans - also depends upon quantification of the fossil fuel flux. This is due to the fact that the net biosphere exchange, in particular, is often calculated as a carbon budget residual accurate assessment of this net exchange, currently responsible for removing roughly $1 / 3$ of the fossil fuel input every year, relies on the accuracy of fossil $\mathrm{CO}_{2}$ flux itself. Moreover, the magnitude, variability and sustainability of this biospheric uptake has emerged as one of the largest sources of uncertainty in climate change projections (Friedlingstein et al., 2006: Cox et al., 2000).

At the spatial scale of the globe and the annual temporal scale, the primary components of the net carbon budget - fossil, biosphere and ocean - have been well quantified. The leading edge of research into the magnitude and variability of these exchanges, however, is now occurring at smaller space/time scales (Denning et al., 2005). More than mere reductionism, the need to downscale is essential to understanding the mechanistic details of these fluxes. This is best accomplished at space and time scales that isolate readily identifiable processes. It also offers the considerable benefit of linking with research communities that have not traditionally viewed themselves as components of this global biogeochemical puzzle: soil scientists, foresters, energy systems engineers, and combustion chemists, to name a few.

Fossil fuel $\mathrm{CO}_{2}$ inventories began as an accounting exercise based on the production/consumption of fossil fuels at the national scale (Marland and Rotty, 1984). In most cases, little sub-national allocation of the emissions was performed because the initial purpose - meeting regulatory commitments (e.g. Kyoto targets) or reconstructing $20^{\text {th }}$ century climate change - required little sub-national information. Thus, the most common spatiotemporal structuring of fossil fuel $\mathrm{CO}_{2}$ emissions occurred at national/annual scales. Starting in the 1980s, research was begun to further subdivide these emissions into finer space and time scales (Rotty 1983; Marland et al., 1985). By the beginning of the $21^{\text {st }}$ century, fossil fuel $\mathrm{CO}_{2}$ emissions had been resolved down to the $1^{\circ} \times 1^{\circ}$ spatial scale and most commonly at an annual time scale (Andres et al., 1996; Olivier et al., 2005) ${ }^{1}$. This downscaling in space and time, however, was achieved through the use of spatial proxies such as population density statistics and nighttim lights (Oda and Maksytov, 2011). Further, temporal downscaling had only been attempted in a comprehensive fashion for the U.S. at a monthly resolution (Andres et al., 1999; Blasing et al., 2005; Gregg and Andres, 2008).

In the last decade, there has been a growing need, from both the science and policymaking communities, for quantification of fossil fuel $\mathrm{CO}_{2}$ emissions at finer space and time scales than this (Gurney et al., 2005; Gurney et al., 2007). Carbon cycle science has required greater accuracy and higher resolution due to the downscaling of carbon budget and inverse approaches, which use space/time patterns of atmospheric $\mathrm{CO}_{2}$ to infer exchange of carbon with the oceans and the terrestrial biosphere (Gurney et al., 2002; Gurney et al., 2008; Denning et al., 2005; Stephens et al., 2007). These scientific needs contributed to the 2009 launches of the Orbiting Carbon Observatory (OCO - failed to reach orbit) and the Greenhouse Gases Observing Satellite (GOSAT).

The policymaking community has also recognized the need for accurate, highly-resolved $\mathrm{CO}_{2}$ emissions due to the emerging requirements of proposed carbon trading systems or sectoral emissions caps. Policymakers also increasingly recognize the need to move beyond broad sectoral quantification and have called for much finer detail in space and time in order to facilitate a more robust trading system. Similar dynamics are playing out at the international scale where verification of emissions for treaty compliance and international carbon trading are viewed as essential elements in successful policy construction (NRC 2010).

This paper describes a progression of research efforts under the purview of the "Vulcan Project", an effort aimed at building a high resolution fossil fuel $\mathrm{CO}_{2}$ data product for North America. In addition to the North American effort, new research has begun that downscales fossil fuel $\mathrm{CO}_{2}$ emissions data products into the landscape of a single city, resolving building-by-building detail and a data product for the global domain in which remote sensing is combined with bottom-up information to estimate fossil fuel $\mathrm{CO}_{2}$ emissions across the planet. Here we describe the methods and summary results of this research and plans for future work.

\footnotetext{
${ }^{1}$ We note that the EDGAR database (Olivier et al., 2005) has recently begun utilizing some spatial proxies beyond just population density.
} 


\section{METHODS}

\subsection{The Vulcan US Data Product}

The total $\mathrm{CO}_{2}$ emissions in the Vulcan inventory are based on data that are reported as a combination of point, area, and linear source classifications. These data classes are ultimately assigned to the following economic sectors: residential, commercial, industrial, electricity production, onroad, nonroad (such as trains, boats, snowmobiles, and lawnmowers), aircraft, and cement production (calcination) (Gurney et al., 2009). Each of these is a combination of more than one data source classification, but the percentage varies by sector (Gurney et al., 2009). For example, the commercial sector is derived from both area and point source reporting whereas the industrial sector is derived almost entirely from point sources. This study focuses on the total on-site fossil fuel combustion $\mathrm{CO}_{2}$ emissions with the following sectoral breakdown: residential, commercial, industrial, electricity production, cement production, and transportation (combination of onroad, nonroad, and aircraft-landing/takeoff and crusing) sectors. The total $2002 \mathrm{CO}_{2}$ emissions from these sectors in the U.S. are 1600 Mt C (Gurney et al., 2009).

The residential and commercial $\mathrm{CO}_{2}$ emissions are predominatly derived from area sources which represent diffuse emissions within an individual U.S. county. The industrial $\mathrm{CO}_{2}$ emissions are dominated by point stationary emitting sources identified to a geocoded location and comprise entities in which emissions exit through a stack or identifiable exhaust feature (USEPA, 2006). The airport source includes emissions associated with geocoded airport locations and represent the take-off/landing cycle (emissions below 3000 feet), taxiing, idling and related aircraft activities on an annual basis (USEPA, 2005a). The point, non-point, and airport data files come from the Environmental Protection Agency's (EPA) National Emissions Inventory (NEI) for the year 2002 (USEPA, 2005b).

In all of these data files - point, nonpoint, and airport sources - we utilize the reported CO emissions. These factors are specific to the combustion process and the fuels tracked in the Vulcan system. CO emission factors are often supplied. Emission factors for $\mathrm{CO}_{2}$ are based on the fuel carbon content and assume a gross calorific value or high heating value. Only emissions associated with fuel combustion are included in the Vulcan estimates. The basic process by which $\mathrm{CO}_{2}$ emissions are created is as follows:

where $\mathrm{x}$ are the $\mathrm{CO}_{2}$ emissions for process $n$ (e.g. industrial $10 \mathrm{MMBTU}$ boiler, industrial gasoline reciprocating turbine) and fuel type $f$ (e.g. natural gas or bituminous coal); $\times$ are the equivalent amount of uncontrolled criteria pollutant emissions $g(\mathrm{CO})$ for process $n$ and fuel type $f ; \square_{-}$is the emission factor associated with the criteria pollutant $g$ for process $n$ and fuel type $f ;{ }^{2}$ is the $\mathrm{CO}_{2}$ emission factor for process $n$ and fuel type $f$ and $O x \%$ is the oxidation factor (100\% for natural gas and $99 \%$ for coal and oil).

Because of the reliability of direct $\mathrm{CO}_{2}$ monitoring and the need for fine time resolution data, we utilize observed $\mathrm{CO}_{2}$ emissions available at electrical generating units (EGUs) (USEPA, 2008). These data contain a large number of facilities that utilize Emission Tracking System/Continuous Emissions Monitoring systems (ETS/CEMs), widely considered the most accurate for $\mathrm{CO}_{2}$ emissions estimation (Pétron et al., 2008). 


\begin{tabular}{|c|c|c|c|c|c|c|c|c|}
\hline Data Source & \multicolumn{4}{|c|}{ National Emissions Inventory (NEI) } & ETS/CEM & NMIM NCD & Aero2k & Portland \\
\hline Data Type & Non-road & Non-point & Point & Airport & $\begin{array}{l}\text { Power } \\
\text { Prod. }\end{array}$ & On road & Aircraft & Cement Prod \\
\hline $\begin{array}{l}\text { Measurement } \\
\text { utilized }\end{array}$ & $\begin{array}{c}\text { Activity/ } \\
\text { population }\end{array}$ & $\mathrm{CO}$ & $\mathrm{CO}$ & $\mathrm{CO}$ & $\mathrm{CO}_{2}$ & $\begin{array}{c}\text { VMT/ } \\
\text { population }\end{array}$ & $\mathrm{CO}_{2}$ & Production \\
\hline $\begin{array}{l}\text { Incoming } \\
\text { resolution: } \\
\text { space/time }\end{array}$ & $\begin{array}{l}\text { County/ } \\
\text { Monthly }\end{array}$ & $\begin{array}{c}\text { County/ } \\
\text { Annual }\end{array}$ & $\begin{array}{c}\text { Lat:Lon/ } \\
\text { Annual }\end{array}$ & $\begin{array}{c}\text { Lat:Lon/ } \\
\text { Ann:Summer }\end{array}$ & $\begin{array}{c}\text { Lat:Lon/ } \\
\text { Hourly }\end{array}$ & $\begin{array}{l}\text { County/ } \\
\text { Monthly }\end{array}$ & $\begin{array}{l}1^{\circ} \times 1^{\circ} \% \\
\text { Monthly }\end{array}$ & \\
\hline $\begin{array}{l}\text { Conditioning } \\
\text { data }\end{array}$ & & $\begin{array}{c}\text { Census, EIA } \\
\text { sales } \\
\text { (sector/state/ } \\
\text { fuel/month), } \\
\text { NARR T } \\
\end{array}$ & $\begin{array}{c}\text { EIA sales } \\
\text { (sector/state/ } \\
\text { fuel/month), } \\
\text { NARR T }\end{array}$ & & & $\begin{array}{l}\text { GIS Road } \\
\text { Atlas/ } \\
\text { Mobile } 6.2\end{array}$ & & \\
\hline $\begin{array}{l}\text { Final } \\
\text { resolution: } \\
\text { space/time }\end{array}$ & $\begin{array}{l}\text { County/ } \\
\text { Monthly }\end{array}$ & $\begin{array}{l}\text { Census tract/ } \\
\text { Monthly }\end{array}$ & $\begin{array}{l}\text { Lat:Lon/ } \\
\text { Monthly }\end{array}$ & $\begin{array}{c}\text { Lat:Lon/ } \\
\text { Annual }\end{array}$ & $\begin{array}{c}\text { Lat:Lon/ } \\
\text { Hourly }\end{array}$ & $\begin{array}{c}\text { Road } \\
\text { Segment/ } \\
\text { Hourly } \\
\end{array}$ & $\begin{array}{l}1^{\circ} \times 1^{\circ} \% \\
\text { Monthly }\end{array}$ & $\begin{array}{c}\text { Lat:Lon/ } \\
\text { Annual }\end{array}$ \\
\hline Sector & Transport & $\begin{array}{l}\text { Comm. } \\
\text { Res. } \\
\text { Ind. } \\
\text { Elec. Prod. }\end{array}$ & $\begin{array}{l}\text { Comm. } \\
\text { Res. } \\
\text { Ind. } \\
\text { Elec. Prod. }\end{array}$ & Transport & Elec. Prod. & Transport & Transport & Cement \\
\hline
\end{tabular}

Figure 1. Data sources and data conditioning used in the Vulcan Project fossil fuel $\mathrm{CO}_{2}$ emissions estimation for the United States

The onroad transportation emissions are based on a combination of county-level data and standard internal combustion engine stochiometry. The county-level data come from the National Mobile Inventory Model (NMIM) County Database (NCD) for 2002 which quantifies the vehicle miles traveled in a county by month, specific to vehicle class and road type (USEPA, 2005c). The Mobile6.2 combustion emissions model is used to generate $\mathrm{CO}_{2}$ emission factors on a per mile basis given inputs such as fleet information, temperature, fuel type, and vehicle speed (USEPA, 2001). Nonroad emissions are structured similarly to the onroad mobile emissions data and consist of mobile sources that do not travel on designated roadways (USEPA, 2005a). The Aero2K aircraft $\mathrm{CO}_{2}$ emissions inventory is directly used to estimate aircraft emissions beyond the takeoff/landing cycle emissions captured in the NEI airport database (Eyers et al., 2004)

Figure 1 provides a simple schematic of the data sources and data conditioning used in the Vulcan Project. Further details regarding the Vulcan methodology can be found in Gurney et al. (2009) and in the detailed Vulcan documentation (http://vulcan.project.asu.edu/pdf/Vulcan.documentation.v2.0.online.pdf).

\section{RESULTS}

Figure 2 shows the Vulcan total 2002 U.S. fossil fuel $\mathrm{CO}_{2}$ emissions, represented on a $10 \mathrm{~km} \times 10 \mathrm{~km}$ grid. Emissions are most readily associated with population centers but interstate highways and concentrations of industrial activity are also evident. Because the incoming data represents a mixture of spatial resolution, the gridded $10 \mathrm{~km}$ emissions map has both a background palette of uniform countylevel emissions and higher resolution points and line sources. This reflects data that was reported at geocoded points, data that was reported at the county level but downscaled to the census tract level, and data which could not be further downscaled from the county scale. This last category shows up as emissions evenly distributed over county areas.

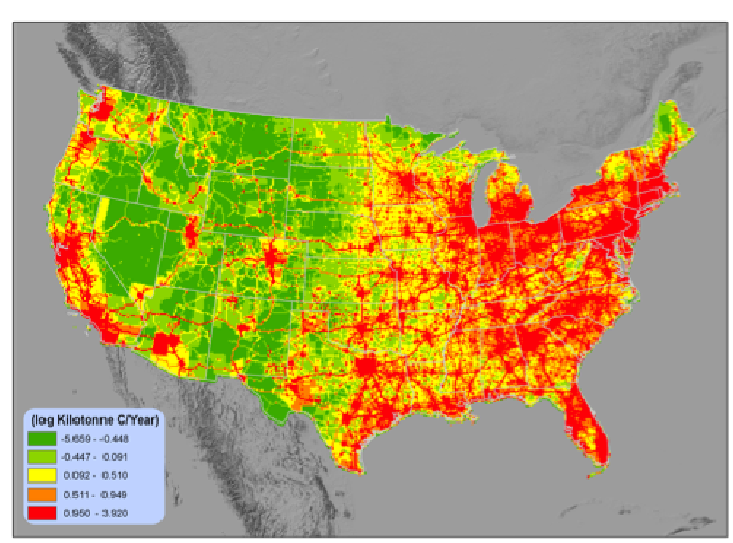

Figure 2. 2002 fossil fuel $\mathrm{CO}_{2}$ emissions from the Vulcan inventory on the common $10 \mathrm{~km}$ grid.

\subsection{Comparison to previous gridded inventory}

A critical goal of the Vulcan research is to contribute to improved quantification of the North American carbon budget, particularly for scales equivalent to, or finer than, the U.S. county level. Due to the accuracy and integrating ability of atmospheric measurements, the total carbon budget is often explored though a combination of surface flux estimation and atmospheric measurements. Hence, we compare the atmospheric concentration of $\mathrm{CO}_{2}$ resulting from the Vulcan inventory to the same derived from the previous inventory used in carbon cycle research (the $1^{\circ} \times 1^{\circ}$ emissions product based on 1995 national-level fossil fuel consumption combined with population density (Andres et al., 1996)). 
The Vulcan inventory estimates higher emissions in the Southeast and along portions of the Texas Gulf coast and less emissions in the Northeast and upper Midwest. Some of this may be due to population migration from 1995 to 2002 but it is more likely due to the decoupling of emissions and population. This is most obvious for electricity production and some industrial sectors which are often not collocated with high population centers. Calculated covariance between the Vulcan sectors and the population-based Brenkert inventory ${ }^{2}$ show the Vulcan electricity production sector having the smallest spatial covariance $(0.072)$ while the Vulcan commercial and residential sectors the highest $(0.65$ and 0.35 , respectively), consistent with expectations that large point sources are increasingly sited away from population centers while commercial and residential emitters are typically collocated with population centers.

The impact these fossil fuel $\mathrm{CO}_{2}$ emissions differences have on atmospheric $\mathrm{CO}_{2}$ concentration differences and biased atmospheric inversion results can be tested. Figure 3 shows estimation of net ecosystem exchange (NEE) from an inversion run for the US domain utilizing the Vulcan Project emissions estimate versus an inversion utilizing the older $1^{\circ} \times 1^{\circ}$ resolution data product (Schuh et al., 2010). The figure shows the resulting bias to the NEE estimation from using the low versus high resolution fossil fuel emissions data products. Large regions of the eastern seaboard show biases on the order of $100 \%$. Large portions of the Midwest and west coast exhibit biases on the order to $50 \%$. Such

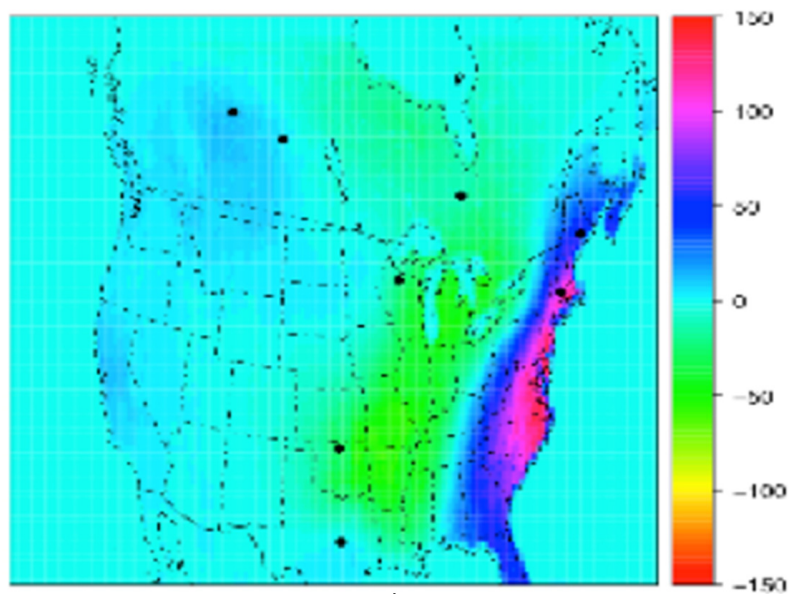

Figure 3. Percent differences in annual net ecosystem exchange inferre Vulcan versus $1 \times 1$ fossil fuel inventories for 2 large biases are unacceptable and remain a challenge to inverse estimation of carbon sources and sinks.

\section{CONCLUSIONS AND RECOMMENDATIONS}

The Vulcan inventory has wide-ranging implications for carbon cycle and climate change research and utility for national legislation on climate change and energy policy. As the largest net land-atmosphere flux, fossil fuel $\mathrm{CO}_{2}$ plays a key role in atmospheric $\mathrm{CO}_{2}$ inversions, widely used to identify and understand the net terrestrial flux. Space/time biases in the fossil fuel flux are directly aliased into the net terrestrial flux in these studies. As inversion studies move to smaller space/time scales, the fossil fuel $\mathrm{CO}_{2}$ flux must be accurately quantified at smaller space/time scales. This is particularly true as remotely sensed $\mathrm{CO}_{2}$ observations become available from the GOSAT mission.

High resolution, process-driven inventories also make possible the incorporation of much finer, processdriven emissions into integrated assessment studies which currently utilize spatially coarse emission projections driven from indirect measures such as population and economic growth.

Finally, high resolution inventories can provide a carbon trading system with a single, science-driven inventory platform. This could widen the scale and sectoral detail for carbon trading. It could also offer a method by which progress in emissions mitigation can be tracked and performance confirmed (Zhou and Gurney, 2011). This last point is crucial in that currently there is no systematic way to evaluate the progress of mitigation measures, an essential component of assessing and judging success as the U.S. constructs legislative measures on climate change mitigation.

Future research direction includes quantifying emissions from Canada and Mexico in order to complete the entire North American inventory. New research has begun on building a fossil fuel $\mathrm{CO}_{2}$ inventory at the scale of individual buildings in near real-time through a combination of in-situ measurements, remote sensing, and energy systems modeling. This project, called "Hestia" is currently utilizing the city of Indianapolis as a first pilot location and is complemented by airborne $\mathrm{CO}_{2}$ flux measurement campaigns from low-flying light aircraft (Zhou and Gurney, 2010). The measurement campaign in coordination with the Hestia Project is called the INFLUX effort and will be the first test of a bottom-up/top-down comparison in an urban domain.

\footnotetext{
${ }^{2}$ http://cdiac.ornl.gov/epubs/ndp/ndp058a/ndp058a.html
} 


\section{ACKNOWLEDGMENTS}

Support for the Vulcan research provided by grant NASA, grant Carbon/04-0325-0167 and DOE grant DEAC02-05CH11231. Computational support provided by the Rosen Center for Advanced Computing (Broc Seib and William Ansley) and the Envision Center (Bedrich Benes and Nathan Andrysco). Thanks to Simon Ilyushchenko of Google Inc., Marc Fischer of Lawrence Berkeley National Laboratory, Dennis Ojima and Steve Knox of Colorado State University for helpful discussion and input.

\section{REFERENCES}

Andres, R.J. Marland, G., Fung, I. and E. Matthews (1996), A 1 x 1 distribution of carbon dioxide emissions from fossil fuel consumption and cement manufacture, 1950-1990, GBC, 10 (3), 419-429.

Andres, R.J., D.J. Fielding, G. Marland, T.A. Boden, N. Kumar and A.T. Kearney (1999), Carbon dioxide emissions from fossil-fuel use, 1751-1950, Tellus, 51B, 759-765.

Blasing, T.J., C.T. Broniak, and G. Marland (2005), the annual cycle of fossil-fuel carbon dioxide emissions in the United States, Tellus, 57B, 107-115.

Cox P.M., Harris P.P., Huntingford C., Betts R.A., Collins M., Jones C.D., Jupp T.E., Marengo J.A., Nobre C.A. (2000) Acceleration of global warming due to carbon-cycle feedbacks in a coupled climate model, Nature, 408, pp. 184-187, November 4.

Denning, A.S. (ed.) (2005), Science Implementation Strategy for the North American Carbon Program. Report of the NACP Implementation Strategy Group of the U.S. Carbon Cycle Interagency Working Group. Washington, DC: U.S. Carbon Cycle Science Program, 68 pp.

Eyers, C.J., P. Norman, J. Middel, M. Plohr, S. Michot, K. Atkinson, and R.A. Christou (2004), AERO2k Global Aviation Emissions Inventories for 2002 and 2025, QINETIQ/04/01113, QinetiQ Ltd, Farnborough, UK.

Friedlingstein, P., P. Cox, R. Betts, L. Bopp, W. von Bloh, V. Brovkin, P. Cadule, S. Doney, M. Eby, I. Fung, G. Bala, J. John, C. Jones, F. Joos, T. Kato, M. Kawamiya, W. Knorr, K. Lindsay, H. D. Matthews, T. Raddatz, P. Rayner, C. Reick, E. Roeckner, K.-G. Schnitzler, R. Schnur, K. Strassman, A. J. Weaver, C. Yoshikawa and N. Zeng (2006), "Climate-carbon cycle feedback analysis, results from the C4MIP model intercomparison," Journal of Climate, 19, 3337-3353.

Gregg, J.S. and R.J. Andres (2008), A method for improving temporal and spatial resolution of carbon dioxide emissions in the United States, Tellus 68B, 1-10.

Gurney, K. R., R. M. Law, A. S. Denning, P. J. Rayner, D. Baker, P. Bousquet, L. Bruhwiler, Y. H. Chen, P. Ciais, S. Fan, I. Y. Fung, M. Gloor, M. Heimann, K. Higuchi, J, John, T. Maki, S. Maksyutov, K. Masarie, P. Peylin, M. Prather, B. C. Pak, J. Randerson, J. Sarmiento, S. Taguchi, T. Takahashi, and C. W. Yuen (2002), Towards robust regional estimates of $\mathrm{CO}_{2}$ sources and sinks using atmospheric transport models. Nature, 415, 626-630.

Gurney, K.R., Y.H. Chen, T. Maki, S.R. Kawa, A. Andrews, Z. Zhu, (2005), "Sensitivity of Atmospheric $\mathrm{CO}_{2}$ Inversion to Seasonal and Interannual Variations in Fossil Fuel Emissions," J. Geophys. Res. 110 (D10), 10308-10321.

Gurney, K.R. W. Ansley, D. Mendoza, B. Seib, G. Petron, G. Frost, J. Gregg, M. Fischer, D. Pataki, K. Ackerman, S. Houweling, K. Corbin, R. Andres and T.J. Blasing (2007), Research needs for processdriven, finely resolved fossil fuel carbon dioxide emissions, EOS, December 4.

Gurney, K.R., D. Baker, P. Rayner, A.S. Denning, and TransCom 3 L2 modelers (2008), "Interannual variations in regional net carbon exchange and sensitivity to observing networks estimated from atmospheric CO2 inversions for the period 1979 to 2006," Global Biogeochemical Cycles, 22, GB3025, doi:10.1029/2007GB003082

Gurney, K.R., D. Mendoza, Y. Zhou, M Fischer, S. de la Rue du Can, S. Geethakumar, C. Miller (2009) The Vulcan Project: High resolution fossil fuel combustion $\mathrm{CO}_{2}$ emissions fluxes for the United States, Environ. Sci. Technol., 43, doi:10.1021/es900806c.

Marland, G. and R.M. Rotty (1984), Carbon dioxide emissions from fossil fuels: a procedure for estimation and results for 1950-1982, Tellus, 36B, 232-261.

Marland, G., R.M Rotty, and N.L. Treat (1985), $\mathrm{CO}_{2}$ from fossil fuel burning: global distribution of emissions, Tellus, 37B, 243-258.

Oda, T. and S. Maksyutov (2011)

Olivier,J., J.A. van Aardenne, F. Dentener, L. Ganzeveld, and J.A.H.W. Peters (2005) Recent trends in global greenhouse gas emissions: Regional trends 1970-2000 and spatial distribution of key sources in $2000, J$. Integr. Env. Sci., 2, doi: 10.1080/15693430500400345.

National Research Council of the National Academies (2010) Verifying Greenhouse Gas Emissions: Methods to Support International Climate Agreements, National Academies Press, Washington DC. 
Pétron, G., P. Tans, G. Frost, D. Chao, and M. Trainer (2008), High-resolution emissions of $\mathrm{CO}_{2}$ from power generation in the USA, J. Geophys. Res., 113, G04008, doi:10.1029/2007JG000602.

Prentice, I.C., and coauthors (2001), The carbon cycle and atmospheric carbon dioxide, in Climate Change 2001, edited by J.T. Houghton et al., pp. 185-225, Cambridge, Univ. Press, New York, 2001.

Rotty, R. (1983), Distribution of and changes in industrial carbon dioxide production, JGR, 88, C2, 13011308

Schuh, A., A.S. Denning, K.D. Corbin, I.T. Baker, M. Uliasz, N. Parazoo, A.E. Andres, and D.E.J. Worthy (2010) A regional high-resolution carbon flux inversion of North America for 2004, Biogeosciences, 7 , 1625-1644.

Stephens, B.B. K.R Gurney, P.P. Tans, C. Sweeney, W. Peters, L. Bruhwiler, P. Ciais, M. Ramonet, P. Bousquet, T. Nakazawa, S. Aoki, T. Machida, G. Inoue, N. Vinnichenko. J. Lloyd, A. Jordan, O. Shibistova, R.L. Langenfelds, L.P. Steele, R.J. Francey, \& A.S. Denning (2007), Weak northern and strong tropical land carbon uptake from vertical profiles of atmospheric CO2, Science, 316, 1732-1735.

United States Environmental Protection Agency (2001), Fleet Characterization Data for MOBILE6: Development and Use of Age Distributions, Average Annual Mileage Accumulation Rates, and Projected Vehicle Counts for Use in MOBILE6, EPA, Washington, DC.

United States Environmental Protection Agency (2005a), Documentation for Aircraft, Commercial Marine Vessel, Locomotive, and Other Nonroad Components of the National Emissions Inventory, Volume I Methodology, EPA, Research Triangle Park, NC.

United States Environmental Protection Agency (2005b), Emissions Inventory Guidance for Implementation of Ozone and Particulate Matter National Ambient Air Quality Standards (NAAQS and Regional Haze Regulations), EPA, Research Triangle Park, NC.

United States Environmental Protection Agency (2005c), EPA's National Mobile Inventory Model (NMIM), A consolidated emissions modeling system for MOBILE6 and NONROAD, EPA, Washington, DC.

United States Environmental Protection Agency (2006), Documentation for the Final 2002 Point Source National Emissions Inventory, Emission Inventory and Analysis Group, Air Quality and Anlysis Division, EPA, Research Triangle Park, NC.

United States Environmental Protection Agency (2008), Clean Air Markets - Data and Maps, Clean Air Markets Division, EPA, Washington, DC.

Zhou, Y. and K.R. Gurney (2010) A New Methodology for Quantifying Residential and Commercial Fossil Fuel $\mathrm{CO}_{2}$ Emissions at the Building Spatial Scale and Hourly Time Scale, Carbon Mngmnt, 1(1), 45-56.

Zhou, Y., and K. R. Gurney (2011), Spatial relationships of sector-specific fossil fuel $\mathrm{CO}_{2}$ emissions in the United States, Global Biogeochem. Cycles, 25, GB3002, doi:10.1029/2010GB003822 